\title{
4MW Class High Power Density Generator for Future Hybrid-Electric Aircraft
}

\author{
D. Golovanov, D. Gerada, G. Sala, Member, IEEE, M. Degano, Member, IEEE, A. Trentin, P. H. Connor, Z. Xu, A. \\ La Rocca, A. Galassini, Member, IEEE, L. Tarisciotti, C. N. Eastwick, S. J. Pickering, P. Wheeler, Fellow Member, \\ IEEE, J. C. Clare, Senior Member, IEEE, M. Filipenko, C. Gerada, Senior Member IEEE
}

\begin{abstract}
This paper describes the underpinning research, development, construction and testing of a 4MW multi-three phase generator designed for a hybrid-electric aircraft propulsion system demonstrator. The aim of the work is to demonstrate gravimetric power densities around $20 \mathrm{~kW} / \mathrm{kg}$, as required for multi-MW aircraft propulsion systems. The key design choices, development procedures and trade-offs, together with the experimental testing of this electrical machine connected to an active rectifier are presented. A time-efficient analytical approach to the down-selection of various machine configurations, geometrical variables, different active and passive materials and different thermal management options is first presented. A detailed design approach based on 3D Finite Element Analysis (FEA) is then presented for the final design. Reduced power tests are carried out on a full scale $4 \mathrm{MW}$ machine prototype, validating the proposed design. The experimental results are in good agreement with simulation and show significant progress in the field of high power density electrical machines at the targeted power rating.
\end{abstract}

Index Terms - Hybrid Electric Aircraft, High-Power Generation Systems, HEA, More-Electric Aircraft, HighPower High-Voltage Machines Design, Multiphase Motors, Aerospace Generator Drives, Variable Speed Drives.

\section{INTRODUCTION}

$\mathrm{W}$ ith air transport being amongst the least green forms of passenger transportation, over the past two decades, the aerospace industry and related bodies have been working intensively on defining aircraft technology roadmaps for the reduction of the net carbon emissions [1].

Various ambitious aircraft emission reduction targets are set, such as those within the EU's Flightpath 2050 program which seeks reductions of $\mathrm{CO} 2$ and $\mathrm{NOx}$ emissions per passenger kilometre by $75 \%$ and $90 \%$, respectively, relative to the year 2000 [2]. In a similar way, NASA, through the Environmentally Responsible Aviation (ERA) work frame, has set targets which include reducing fuel burn by $50 \%$, and NOx emissions by $75 \%$ [3]. The aforementioned programs are tackling the current aircraft emissions problem through different approaches, which involve the improvement of the existing combustion technologies, while looking for new disruptive technologies, amongst which hybrid-electric and allelectric architectures are gaining increased focus. In the nearer term, targeting the narrow-body aircraft market, which globally consumes over half of the aviation fuel, hybrid-electric solutions have the potential to revolutionise aircraft propulsion and generation systems, combining the advantages of fuelbased systems and battery powered systems, whilst offering new degrees of design freedom for efficient aircraft configurations and systemic synergies [4]. One prominent example in this area was the E-Fan $\mathrm{X}$ ground demonstrator, which has brought together two key European companies, namely Airbus and Rolls-Royce, jointly developing a hybridelectric propulsion system involving a $2 \mathrm{MW}$ electric drive supplied from a $2.5 \mathrm{MW}$ generator that is powered by a gas turbine situated in the fuselage [5]. Whilst the project has been concluded and will not fly as originally planned, ground testing of the Rolls-Royce system will continue. Other programs, that have seen the involvement of international consortia comprising industrial, research and academic institutions, are moving in a similar direction by exploring revolutionary aircraft technologies [6], [7]. To make hybrid-electric aircraft fly, the continuous power density and efficiency of the electrical machines used for propulsion and generation both need to be pushed beyond the current state of the art [8]. The challenges in achieving high power densities are compounded by the $\mathrm{kV}$-level insulation requirements at altitude, which demand a sensitive balance between the thermal dissipation and the lifetime. More concepts and case studies for civilian hybrid-electric aircraft have been considered, focusing on both propulsion and generation [9], [10]. However, to date, there are a very limited number of MW-class, $\mathrm{kV}$-level demonstrators in the literature, where both power and power density meet the challenging requirements for future hybrid-electric aircraft.

In terms of high power electrical machines, one of the largest developments is reported in [11], where some preliminary results of a Mark\#1 2.5 MW permanent magnet generator are promising. There is a series of publications recently presented that investigate various topologies - [12], [13], and concepts [14], [15] of electrical machines that could be considered as candidates for propulsion system of future hybrid-electric aircraft. Taking into account the technology readiness and high requirements for efficiency, power density and reliability, electrical machines with permanent magnets (PM) are a promising topology to fit the criteria for hybrid-electric propulsion systems [16], [17].

This work aims to present and demonstrate the challenges in developing a 4 MW (5 MVA), 15,000 rpm, electrical machine suitable for the future hybrid-electric aircraft on-board generating systems, by targeting a record power-density of 18 $\mathrm{kW} / \mathrm{kg}$ (including active and passive components). The paper also presents an architecture of a high-power medium-voltage drive, featuring a high-speed multiphase machine with an 8pole permanent magnet rotor and multiple isolated three-phase windings in the stator.

The hybrid turbo-electric architecture layout considered within this study is sketched in Fig. 1. Starting from the left- 
hand side of the schematic, a gas turbine $(\mathrm{T})$ is driving an electrical generator $(\mathrm{G})$ connected to an $\mathrm{AC} / \mathrm{DC}$ converter with two separate isolated channels (BRAVO and ECHO). This project has focused on the combined sub-system highlighted within the orange box.

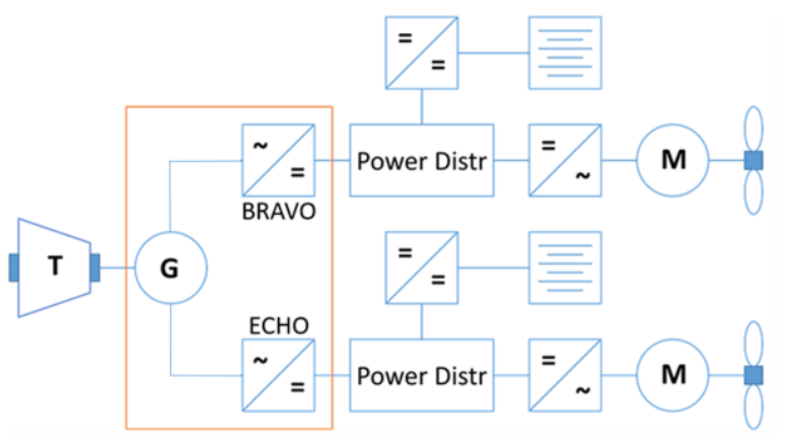

Fig. 1 Schematic of the drive train system. Component ' $G$ ' is the electrical machine (Generator) and BRAVO and ECHO are two channels of the converter, which is connected to the power distribution system.

The paper is organised as follows. In Section II, the design choices for a 4 MW (5 MVA) generator are presented, highlighting pros and cons of different machine topologies. In Section III, the detailed design and proposed three-stage optimisation methodology of the selected machine topology are described. The generator is prototyped and experimentally validated, with the results discussed in Section IV. Finally, the conclusions and key outcomes from this work are discussed in section V. The novelty of the paper is a demonstration of a breakthrough power density at the MW power-levels reached by using innovative machine optimisation methodologies, which exploit improved material properties and advanced thermal management techniques.

\section{SELECTION OF THE MACHINE TOPOLOGY}

In the earlier stages of this research program, trade off studies were conducted with four different topologies of PM machines considered and optimised: outer rotor (OR), inner rotor (IR), double stator (DS) and double rotor (DR) designs, as presented in [18]. In this work it has been shown, as a case study, that 1 MW machine with DR topology can enable power densities up to $26 \mathrm{~kW} / \mathrm{kg}$ and $34 \mathrm{~kW} / \mathrm{kg}$ at $14,000 \mathrm{rpm}$ and $20,000 \mathrm{rpm}$, respectively. The solutions with IR design resulted in the second-best option, with corresponding power densities around $18 \mathrm{~kW} / \mathrm{kg}$ and $23 \mathrm{~kW} / \mathrm{kg}$, at the same reference speeds. With the boundaries of the aforementioned study, the optimisation results for both OR and DS designs showed comparatively lower power density values compared to DS and IR. Therefore, the OR and DS configurations were not considered as potential candidates to pursue for building a higher power prototype. Although the DR machine shows an outstanding power density, the mechanical complexity introduced by the additional rotor and its comparatively lower technology readiness level (TRL) limit its use in high power systems. For practical reasons and in seeking to develop a higher TRL MWclass demonstrator, the IR configuration with a Halbach array was selected as the topology to take forward for the development of an aircraft ground demonstrator capable of generating 5 MVA (4 MW) of power. The rotor of the IR generator consists of a Halbach cylinder made from samariumcobalt (Sm2Co17) permanent magnets (PM), as shown in Fig. 2. The samarium-cobalt PMs were selected due to the higher thermal stability compared to neodymium-based PMs.

The material of the stator core is cobalt-iron $(49 \% \mathrm{CoFe})$ since it exhibits the best-in-class material saturation properties, as well as good specific loss characteristics. It was published in [19] that cobalt-iron steel enables achieving the highest power density at the best efficiency, in comparison with standard or high-grade silicon electrical steel.

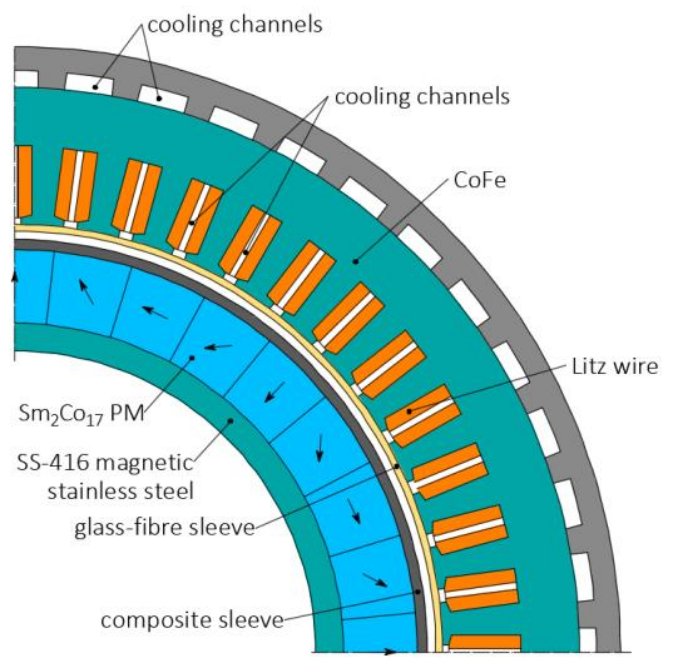

Fig. 2: Synchronous IR permanent magnet machine with Halbach array.

The PMs are retained by a composite rotor sleeve. The rotor core is made from magnetic stainless steel that enhances the air-gap flux density produced by the Halbach magnet array, thereby allowing higher power densities to be reached.

With relatively low iron losses (due to low specific loss characteristics of the core material, optimised winding design and good current waveform THD), and with high armature current densities, the windings need to be intensively cooled. Cooling channels are located in the middle of the slots allowing delivery of the coolant directly to the heat generation source of the majority of the losses (i.e. the winding). The end-windings are cooled by oil jet impingement, while the stator core is cooled by an oil jacket, as shown in Fig. 3. The rotor is separated from the stator by $1.2 \mathrm{~mm}$ glass-fibre sleeve, creating a wet-zone (stator), and a dry-zone (rotor) in order to keep the windage losses low [20].

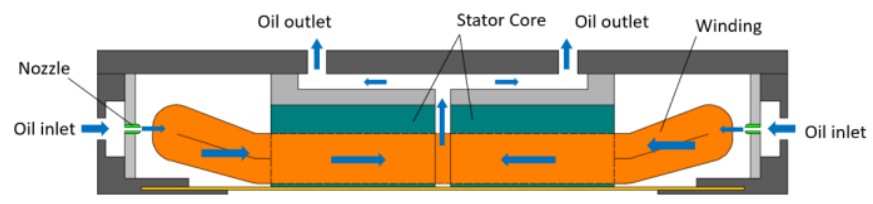

Fig. 3: Schematic to show coolant path within the generator.

\section{DESCRIPTION OF THE MACHINE OPTIMISATION PROCESS}

The technical requirements for the generator are listed in Table 1. The requested back-Electromotive Force (bEMF), phase current and phase voltage are derived from the power electronic converter to meet the input requirements of its eight 
3-phase subsystems. In particular, to split the power among the power electronic devices, the 3-phase sub-windings are fed by series and parallel modules of the converter, respectively, to meet the $3 \mathrm{kV}$ DC link requirement [21]. A key requirement for this generator is the ability to operate with unbalanced loading across its sub-systems, including continuous operation in the event of faults. The generator and converter are cooled by the same fluid (oil) with a maximum flow rate capability of 500 $1 / \mathrm{min}$ and with an inlet temperature of $90^{\circ} \mathrm{C}$. The generator is designed to be directly coupled to a gas turbine and is designed for a mechanical rotational speed of $15,000 \mathrm{rpm}$, considering an overspeed capacity of $20 \%$ (equivalent to $18,000 \mathrm{rpm}$ ).

The machine design optimisation procedure comprises three main design stages, conducted sequentially, which are summarised in the flowchart shown in Fig. 4.

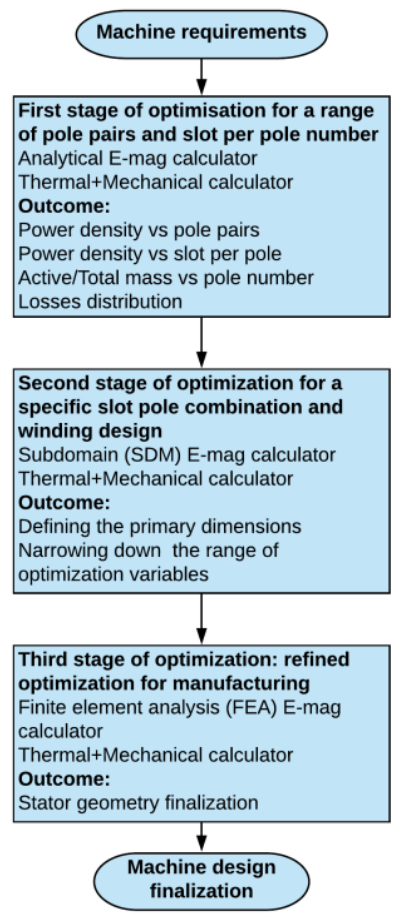

Fig. 4: Machine optimisation flowchart.

The procedure starts from the first stage, which is analytical and includes electromagnetic analysis as well as the thermal and mechanical calculations. The aim of this step is to define the correlation of the machine power density versus the numbers of poles and slots per pole. At this stage, the winding layout is assumed to be a standard 3-phase single layer one, with a single turn per coil. The machine is analysed in the generating mode with $\mathrm{Id}=0$ assuming the surface permanent magnet (SPM) machine without magnetic anisotropy between $\mathrm{d}$ and $\mathrm{q}$ axes $(\mathrm{Xd}=\mathrm{Xq})$.

This is followed by the second stage of optimisation which is performed for a specific pole-slot combination and a winding layout which considers a multi-three phase system, made by $8 \mathrm{x}$ 3 -phase sets, for the case in hand. This is done using the socalled subdomain model (SDM), which is purely analytical, but more accurate than a standard analytical calculator, and allows capture of the slotting effect, the direction of magnetisation of each PM segment of Halbach array, the impact of PM segmentation, the winding arrangement and the coil design [22]. The primary machine dimensions such as the stator inner diameter, rotor outer diameter, PM height and rotor sleeve thickness are defined at this stage, while the range of other input variables such as tooth width, tooth height, stator outer diameter and machine length is narrowed down.

The rotor sleeve thickness was parametrized to get an optimal value and not over or underestimate its dimension. The rotor sleeve mechanical stress was at each iteration of the optimization procedure for the $1^{\text {st }}$ and $2^{\text {nd }}$ stage by analytical formulation taking into account a safety factor of 2 . For the final design, the sleeve mechanical stress was refined by FEA. The rotor sleeve pre-stress condition is not considered during the optimization process, it was later confirmed at the optimization stage 3 using FEA analysis during the design embodiment phase and confirmed by the rotor manufacturer, who have detailed experience with pre-stressed rotor sleeves.

The final (third) optimisation stage, shown in Fig. 4, is performed by Finite Element Analysis (FEA) considering the material saturation effect. The stator slot dimensions, the stator outer diameter, and the axial length of the machine are finalised including manufacturing considerations.

Table 1 - LIST OF REQUIREMENTS FOR THE GENERATOR

\begin{tabular}{cc}
\hline Requirement & Value \\
\hline Continuous power & $4,000 \mathrm{~kW}$ \\
Mechanical rotational speed & $15,000 \mathrm{rpm}$ \\
Power factor $(\mathrm{PF})$ & $\geq 0.8$ \\
Phase bEMF (rms) & $400 \mathrm{~V}$ \\
Phase Voltage (rms) & $500 \mathrm{~V}$ \\
Phase Current (rms) & $416 \mathrm{~A}$ \\
DC link & $3 \mathrm{kV}$ \\
\hline Efficiency & $\geq 97 \%$ \\
Maximum coolant flow rate & $500 \mathrm{l}$ \\
\hline Inlet temperature of the coolant & $90{ }^{\circ} \mathrm{C}$ \\
\hline Number of phases & $8 \times 3$ \\
\hline Stator outer diameter & $<400 \mathrm{~mm}$ \\
\hline \hline
\end{tabular}

\section{A. First stage of optimization}

The commercial optimisation software 'ModeFrontier' is used allowing for a selection of optimisation algorithms (Simplex, Multi-Objective Genetic Algorithm - MOGA, Particle Swarm, etc.), which can link to the developed analytical/numerical calculators [18], [23]. The list of input variables and constraints for the first stage of the optimisation is given in [18]. At the most fundamental level, the main dimensions of the machine can be described via seven input variables: (i) $k$ is the stator outer to inner diameter ratio, (ii) $S_{O D}$ the stator outer diameter, (iii) aspect ratio $k_{\text {form }}$, expressed as active length to stator inner diameter ratio, (iv) PM height, (v) sleeve thickness $S L_{t h}$ together with (vi) tooth width and (vii) tooth height coefficients, which define the tooth dimensions, respectively. The single-objective function is the maximisation of power density of the generator. The constraints to this optimisation were set both by the requirements and material limitations (see the Table 2). The detailed description of how the optimisation software ModeFrontier is coupled to the electromagnetic analytical model is given in [18]. At this stage, a hybrid optimisation algorithm is utilised. It combines the global exploration capabilities of genetic algorithms with local exploitation guaranteed by Sequential Quadratic Programming 
(SQP) implementations. About 15000 designs were evaluated for each pole-slot combination.

In order to limit the fundamental frequency to a maximum acceptable value for the active rectifier, the possible pole pair number is considered in the range from 2 to 6 , with the corresponding fundamental electrical frequency being in the range from $500 \mathrm{~Hz}$ to $1,500 \mathrm{~Hz}$. This is also related to the switching-fundamental frequency ratio which was set to 10 as a lower limit. According to the requirements, the PF constraint was set to $>0.8$, efficiency constraint to $>0.97$ and the stator outer diameter to $<400 \mathrm{~mm}$. The saturation of the stator material $(49 \% \mathrm{CoFe})$ is not considered at this stage. To discard non-realistic designs the tooth and core flux density constraints were set to $<2.1 \mathrm{~T}$. The limit for the coil hotspot temperature was set to $200{ }^{\circ} \mathrm{C}$, which is still a high value of temperature, despite the direct oil cooling of the winding. This is due to the high power density of the machine, and the inevitable thermal resistances introduced by the high-voltage turn to turn insulation. The thermal boundary conditions are the oil inlet flow rate, and inlet temperature as the heat generated in the machine is removed by the forced oil flow through the machine. The heat transfer coefficients are calculated based on the flow rate, and therefore velocities, of oil impingement and oil forced channel flow in slot. The list of input variables and constraints is presented in Table 2, where the key objective is the maximisation of the gravimetric power density with a target power of $4 \mathrm{MW}$.

Table 2 - LIST OF INPUT VARIABLES AND CONSTRAINTS FOR THE FIRST STAGE OF OPTIMISATION

\begin{tabular}{|c|c|c|c|c|}
\hline & Symbol & Expression & $\begin{array}{l}\text { Range or } \\
\text { limit }\end{array}$ & Description \\
\hline \multirow{8}{*}{ 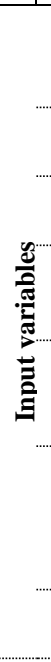 } & $k$ & $\frac{S_{O D}}{S_{I D}}$ & $1.2-2$ & $\begin{array}{l}\text { Stator } \\
\text { diameters' } \\
\text { ratio }\end{array}$ \\
\hline & $S_{I D}$ & $x$ & $\begin{array}{l}200- \\
350 \mathrm{~mm}\end{array}$ & $\begin{array}{l}\text { Stator inner } \\
\text { diameter }\end{array}$ \\
\hline & $k_{-}$form & $\begin{array}{c}L_{a} / S_{I D} ; L_{a}-\text { active } \\
\text { length }\end{array}$ & $0.75-2.5$ & Aspect ratio \\
\hline & $M_{\text {height }}$ & $x$ & $5-30 \mathrm{~mm}$ & PM height \\
\hline & & $6 p T_{\text {width }} \cdot S P P$ & & \\
\hline & $T W_{\text {coeff }}$ & $\begin{array}{cc}\bar{\pi} & S_{I D} \\
T_{\text {width }}-\text { tooth width }\end{array}$ & $0.3-0.8$ & $\begin{array}{l}\text { looth width } \\
\text { coefficient }\end{array}$ \\
\hline & $T H_{\text {coeff }}$ & $\begin{array}{c}\frac{2 T_{\text {height }}}{S_{O D}-S_{I D}} \\
T_{\text {height }}-\text { tooth } \\
\text { height }\end{array}$ & $0.3-0.8$ & $\begin{array}{l}\text { Tooth height } \\
\text { coefficient }\end{array}$ \\
\hline & $S L_{t h}$ & $x$ & $3-10 \mathrm{~mm}$ & $\begin{array}{l}\text { Rotor sleeve } \\
\text { thickness }\end{array}$ \\
\hline \multirow{7}{*}{ ن } & $P F$ & $x$ & $>0.8$ & Power factor \\
\hline & $E f f$ & $x$ & $>0.97$ & Efficiency \\
\hline & Btooth $_{\text {Load }}$ & $x$ & $<2.1 \mathrm{~T}$ & $\begin{array}{l}\text { Tooth flux } \\
\text { density }\end{array}$ \\
\hline & Bcore $_{\text {Load }}$ & $x$ & $<2.1 \mathrm{~T}$ & $\begin{array}{l}\text { Core flux } \\
\text { density }\end{array}$ \\
\hline & $T_{\text {coil }}$ & $x$ & $<200^{\circ} \mathrm{C}$ & $\begin{array}{l}\text { Coil } \\
\text { temperature }\end{array}$ \\
\hline & $S L_{\text {safe }}$ & $x$ & $>2$ & $\begin{array}{l}\text { Sleeve } \\
\text { safety factor }\end{array}$ \\
\hline & $S_{O D}$ & $x$ & $<400 \mathrm{~mm}$ & Stator Outer \\
\hline
\end{tabular}

\begin{tabular}{lll} 
Sl_Ch_W & $\times 3 \mathrm{~mm}$ & $\begin{array}{l}\text { Diameter } \\
\text { Slot cooling } \\
\text { channel } \\
\text { width }\end{array}$ \\
\hline
\end{tabular}

Within this range, the Halbach PM array is assumed to be sinusoidal with the radial component of fundamental air-gap flux density distribution calculated by using equation (1) [24].

$$
B_{I r}=B_{r} \frac{p}{1+p} \frac{1-\left(\frac{R_{r}}{R_{m}}\right)^{p+1}}{1-\left(\frac{R_{r}}{R_{S}}\right)^{2 p}}\left[\left(\frac{r}{R_{s}}\right)^{p-1}\left(\frac{R_{m}}{R_{S}}\right)^{p+1}+\left(\frac{R_{m}}{r}\right)^{p+1}\right] \cos (p \theta)
$$

Here $B_{r}$ is the PM remanence, $p$ is the pole pair number, $R_{s}$ is the stator bore radius, $R_{r}$ and $R_{m}$ are the PM inner and outer radii, respectively. The parameters $r$ and $\theta$ are the polar coordinates of the point of the field observation.

The results of the first stage optimisation are shown in Fig. 5. It should be mentioned that there were no feasible designs found for 2 pole pairs and 1 slot per pole per phase (SPP) configuration, due to the temperature constraint and the applied cooling technique. Likewise, no feasible designs were found for 5 and 6 pole pairs with 2 SPP. It can be seen that the power density gradually increases from $7.6 \mathrm{~kW} / \mathrm{kg}$ to $14.2 \mathrm{~kW} / \mathrm{kg}$ for the 1 slot per pole per phase case while for the 2 SPP design the power density increases from $5.8 \mathrm{~kW} / \mathrm{kg}$ to $15 \mathrm{~kW} / \mathrm{kg}$.

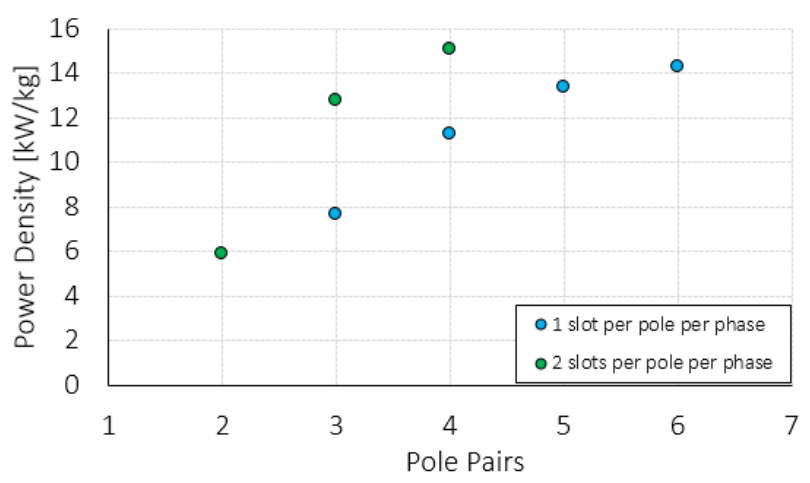

Fig. 5: Power density variation with pole pairs and slot per pole per phase number.

When the constraint of slot cooling channel width is set to $S l_{C h, W}>3 \mathrm{~mm}$ no feasible results are obtained for 2 SPP with 5 and 6 pole pairs, since with the increasing number of slots the cooling channel constraint leads to machine outer diameter growth, which exceeds the limit of $400 \mathrm{~mm}$.

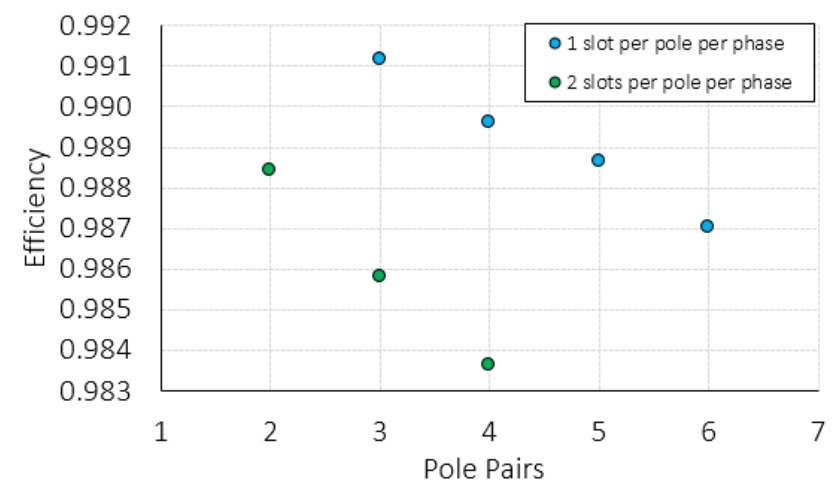

Fig. 6: Efficiency variation with pole pairs and slot per pole per phase number. 
Fig. 6 shows the trend of the machine efficiencies with respect to the number of pole pairs. This drops from $99.1 \%$ to $98.7 \%$ for 3 and 6 pole pair designs with 1 SPP, respectively. For a 2 SPP configuration, the efficiency drops from $98.8 \%$ down to $98.4 \%$ when increasing the pole pair number from 2 to 4 .

The loss distribution for the aforementioned optimised set of designs is presented in Fig. 7. The dominant component of the power loss originates from the copper loss, while the iron loss component increases with the pole pair number due to the rise of the electrical frequency. The total loss in the 5 MVA generator changes from $36.8 \mathrm{~kW}$ to $54.6 \mathrm{~kW}$ for the 1 SPP designs and in the range from $48.3 \mathrm{~kW}$ to $84.9 \mathrm{~kW}$ for the 2 SPP designs. Owing to the smaller slot dimensions in the machines with a higher pole count, there is a shorter thermal path from the heat sources in the coils, teeth and core volumes to the coolant. Also, with the increase in the number of poles, the stator core thickness reduces. These characteristics enable increased cooling efficiency and extracting more heat without exceeding the set winding temperature limit of $200{ }^{\circ} \mathrm{C}$. The mechanical calculator part of the analytical model, for an arbitrary active geometry calculates the inactive mass. This includes consideration of the required torque-transmission (for shaft sizing), rotational dynamics, rotor sleeve stress, bearing mass, together with the mass of the active parts [18], [25]. The passive components comprise the following: housing and endcaps, rotor shaft, rotor balance plates, rotor magnet retention sleeve, bearings, connectors, stator oil sleeve, bearing housing.

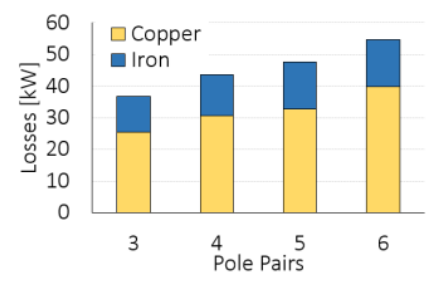

a)

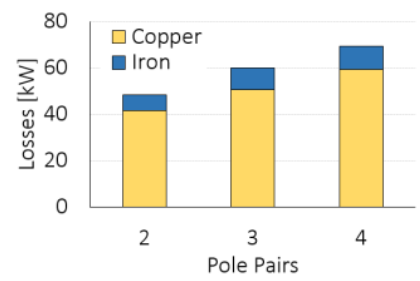

b)
Fig. 7: Loss distribution variation with pole pair; (a) - 1 SPP; (b) -2 SPP.

Thus, in the presented approach, in seeking the optimal power density $(\mathrm{kW} / \mathrm{kg})$ the passive mass is factored into the holistic optimisation. This is different compared to traditional approaches where first the active mass is minimised and then the inactive parts are subsequently added.

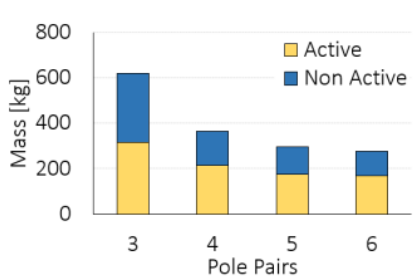

a)

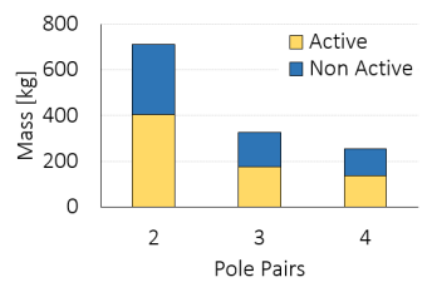

b)
Fig. 8: Mass segregation variation with pole pair; (a) - 1 SPP; (b) - 2 SPP.

Fig. 8 presents the active to total mass ratio, which varies in the range from 0.53 to 0.57 for the investigated designs. It can be seen from the diagrams that for the lower pole number the machine outer diameter tends to be bigger due to the thicker magnets and larger stator core. This automatically leads to larger housing outer diameter, which is the main component that contributes to the passive mass of the machine. The results of the described first stage of optimisation allow for down selecting the suitable range of the main machine parameters. Considering the factors presented, the 4 pole pair configuration with 2 SPP is taken to the next stage of development since it exhibits the highest power density among the considered designs. Also, this solution leads to a fundamental frequency of $1,000 \mathrm{~Hz}$, which is a good match with the power modules to be used within the converter. In fact, a higher value would have required an increase of the switching frequency of the converter, which is limited by the high-power Insulated-gate bipolar transistor (IGBT) modules commercially available on the market.

Fig. 9 illustrates the schematic of the architecture of the converter employed for the generator, comprising 4 parallel layers of two series 3-phase neutral point converters (NPCs) each, for a total of $8 \times 3$-phase sub-windings. The $8 \times 3$-phase configuration naturally fits the 4 pole pair 48-slots configuration selected [21].

A simplified version of winding layout is also presented in Fig. 9. The phases $A_{1} B_{1} C_{1}$ and $A_{2} B_{2} C_{2}$ have an electrical phase shift of $30^{\circ}$ and belongs to adjacent phases of BRAVO and ECHO. All the other 3-phase winding systems are identical to $\mathrm{A}_{1} \mathrm{~B}_{1} \mathrm{C}_{1}$ and $\mathrm{A}_{2} \mathrm{~B}_{2} \mathrm{C}_{2}$.
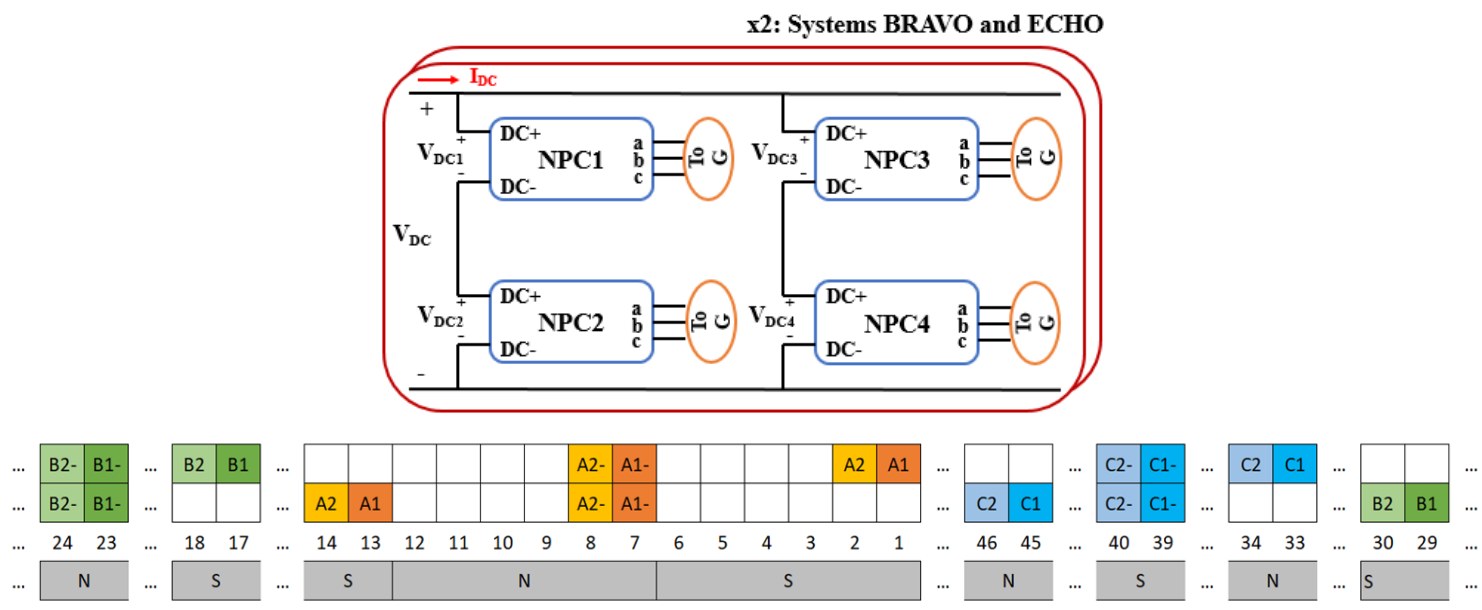

Fig. 9: Full 8x3-phase converter comprised of two $3 \mathrm{kV}$ DC-Link channels and 8x3-phase winding layout 


\section{B. Second stage of optimization}

The second stage of optimisation is performed by using a subdomain analytical modelling technique (SDM) [26], [27], [28]. The SDM model is based on the direct solution of Laplace's and Poisson's equations within the four domains of the machine, as shown in Fig. 10, namely the PM, air gap, slot opening and slot regions. These can be represented by the following equations:

$$
\begin{array}{ll}
\Delta \mathrm{A}_{\mathrm{so}}=0, \Delta \mathrm{A}_{\mathrm{g}}=0 & \text { for air-gap and slot opening } \\
\Delta \mathrm{A}_{\mathrm{s}}=-\mu_{0} \mathrm{~J} & \text { for the slot } \\
\Delta \mathrm{A}_{\mathrm{PM}}=\mu_{0} \nabla \times \mathrm{M} & \text { for the PMs }
\end{array}
$$

The detailed solution of (2) - (4) is described in [26], [28].

The set of input variables for this second stage optimisation are listed in Table 3. The variables' range is narrowed down compared to the first stage of optimisation.

At this stage, the machine is optimised for the selected $8 \times 3$ phase winding layout. There are $4 \times 3$-phase systems which are controlled by ECHO, while the other $4 \times 3$-phases are controlled by the BRAVO channel of the converter.

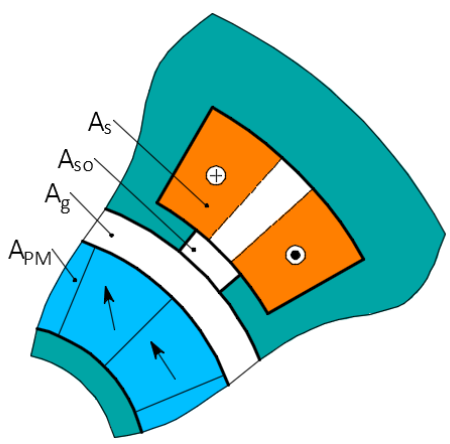

Fig. 10: Schematic showing the geometry of the SDM model.

The independent control of the current in the channels with the phase shift of $30^{\circ}$ between ECHO and BRAVO 3-phase systems allows increasing the torque by $3.4 \%$ compared to the solution without phase shift between 3-phase systems.

The main assumption of the SDM model is the linear behavior of the materials. However, due to the high efficiency requirement and the use of $\mathrm{CoFe}$ lamination material, the design is not expected to have significant iron saturation, leading to a reasonable use of this approach for an

\begin{tabular}{|c|c|c|}
\hline Symbol & Input Range & Optimal Value \\
\hline$k$ & $1.2-2$ & 1.42 \\
\hline$S_{I D}$ & $235-285 \mathrm{~mm}$ & $273 \mathrm{~mm}$ \\
\hline$k_{\text {form }}$ & $0.85-1.1$ & 0.915 \\
\hline$M_{\text {height }}$ & $27-30 \mathrm{~mm}$ & $29 \mathrm{~mm}$ \\
\hline$T W_{\text {coeff }}$ & $0.35-0.45$ & 0.41 \\
\hline$T H_{\text {coeff }}$ & $0.55-0.7$ & 0.6 \\
\hline$S L_{t h}$ & $6.8-8.3 \mathrm{~mm}$ & $7.4 \mathrm{~mm}$ \\
\hline
\end{tabular}
'intermediate' design optimisation.

Table 3 - INPUT VARIABLES FOR SDM OPTIMISATION

The feasible designs of the second stage of optimisation with the target function of the machine power density maximisation for the case of 2 PMs and 4 PMs segments per pole pitch are given in Fig. 11 which shows the correlation of power density, efficiency and current density. About 10000 design were evaluated at this stage for each case of PMs segments. The optimal machine design selected at this stage has 4 PMs per pole, power density of $16.1 \mathrm{~kW} / \mathrm{kg}$ and an efficiency of $98.5 \%$. The comparison of main parameters of the optimal designs for the case of 2 and 4 PMs segments per pole are presented in the Table 4.
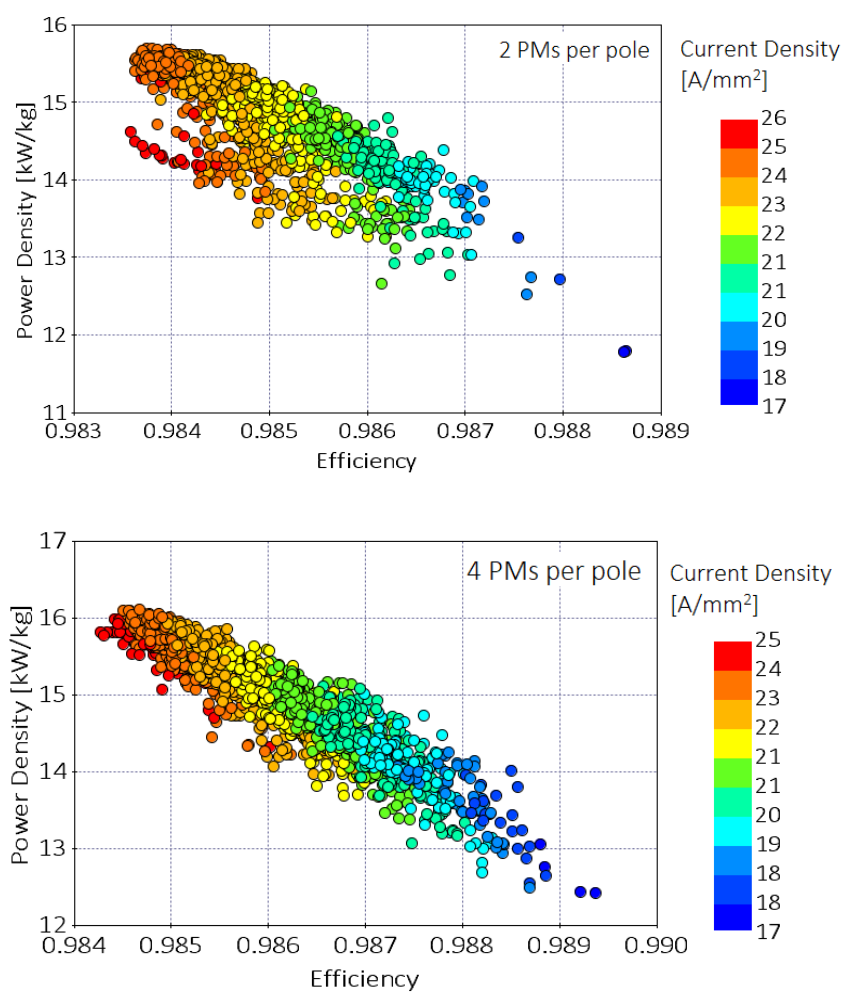

Fig. 1 - Comparison of the optimal design layouts - correlation of power density against efficiency, current density.

It can be seen from the Table 4 that the design with 4 magnet segments has both higher the power density as well as the efficiency: $16.1 \mathrm{~kW} / \mathrm{kg}$ against $15.7 \mathrm{~kW} / \mathrm{kg}$ and $98.5 \%$ against $98.4 \%$, respectively. For two magnet segments only radial and tangential direction of magnetisation (DOM) of PM in the rotor has been taken into account, whereas magnets with $45^{\circ} \mathrm{DOM}$ are introduced for the four-segment layout. The latter allows increasing the flux density in the air gap, achieve a more sinusoidal field distribution and improve the power density without sacrificing the efficiency of the machine.

\begin{tabular}{|c|c|c|}
\hline Basic Output Parameters & $\begin{array}{c}2 \text { PMs per pole } \\
\text { pitch }\end{array}$ & $\begin{array}{c}4 \text { PMs per pole } \\
\text { pitch }\end{array}$ \\
\hline Total mass $[\mathrm{kg}]$ & 255 & 248 \\
\hline Active mass $[\mathrm{kg}]$ & 130 & 126 \\
\hline Passive mass $[\mathrm{kg}]$ & 125 & 122 \\
\hline Power density $[\mathrm{kW} / \mathrm{kg}]$ & 15.7 & 16.1 \\
\hline Efficiency & 0.984 & 0.985 \\
\hline Current density $\left[\mathrm{Arms} / \mathrm{mmcu}^{2}\right.$ & 24.4 & 23.5 \\
\hline Coil temperature $\left[{ }^{\circ} \mathrm{C}\right]$ & 200 & 200 \\
\hline Power factor & 0.84 & 0.85 \\
\hline
\end{tabular}

Table 4 - THE OUTPUT PARAMETERS OF THE OPTIMISED MACHINE (SECOND STAGE - 'SDM' MODEL) 


\begin{tabular}{lcc}
\hline Iron loss $[\mathrm{kW}]$ & 10.0 & 10.9 \\
\hline Copper loss $[\mathrm{kW}]$ & 56 & 51 \\
\hline Total loss $[\mathrm{kW}]$ & 66.0 & 61.9 \\
\hline \hline
\end{tabular}

\section{Third stage of optimisation and the machine design} finalization

As investigated in [29] [30] [31] at high fundamental frequency the AC copper losses can be significant and very sensitive on the type and position of the wire. In case of bulk (thick) conductors such as Roebel bars or hairpin wires the proximity effect causes eddy current circulation in the copper, which leads to additional heat generation. On the other hand, using of conventional round wires with a suitable diameter requires connecting several strands in parallel within a bundle. As described in [32] and [33] employing parallel strands causes additional AC loss due to the circulating current between the strands. In addition, these AC losses are quite difficult to predict since they are very sensitive to the strands' and bundle arrangements within each slot. To suppress proximity effects and circulating currents within the winding, Litz wire is selected and considered in this work.

Before the third stage of optimisation, several winding trials were made to check the technical feasibility of the coils, the dimension of the end- winding overhang, together with the practical implementation of the winding procedure. The decision to make an open slot design was taken at this stage since it allows for preforming the coils and then inserting them into the slots.

The initial range of input variables for FEA optimisation is listed in Table 5. These variables fully define the stator geometry. The other input variables such as sleeve thickness $\mathrm{SL}_{\text {th }}, \mathrm{PM}$ height $\mathrm{M}_{\text {height }}$ and stator inner diameter $\mathrm{S}_{\mathrm{ID}}$ which determine the rotor dimensions were fixed after SDM optimisation. About 2500 design were evaluated at the third stage of optimisation. It should be noted that the thermal model used for the $3^{\text {rd }}$ stage is the same as for the stage 1 and 2. A more detailed CFD analysis was performed as a separate investigation for the final machine design.

Table 5 - INPUT VARIABLES FOR FEA OPTIMISATION

\begin{tabular}{c|c|c|l}
\hline \hline Symbol & Input Range & $\begin{array}{c}\text { Optimal } \\
\text { Value }\end{array}$ & Description \\
\hline$T W_{\text {coeff }}$ & $0.36-0.4$ & 0.37 & Tooth width coefficient \\
\hline$T H_{\text {coeff }}$ & $0.6-0.7$ & 0.65 & Tooth height coefficient \\
\hline$k$ & $1.33-1.47$ & 1.38 & $\begin{array}{l}\text { Stator diameters ratio } \\
\left(L_{a} / S_{I D}\right)\end{array}$ \\
\hdashline$k_{\text {form }}$ & $0.7-1$ & 0.77 & Aspect ratio $\left(\frac{S_{O D}}{S_{I D}}\right)$ \\
\hline \hline
\end{tabular}

The feasible designs are presented in Fig. 12, in the key power-density vs. efficiency correlation. The design with the highest power density of $17.3 \mathrm{~kW} / \mathrm{kg}$, with the optimal input variables listed in Table 5, was chosen for manufacturing a full scale prototype. The main parameters of the final machine design are provided in Table 6 .

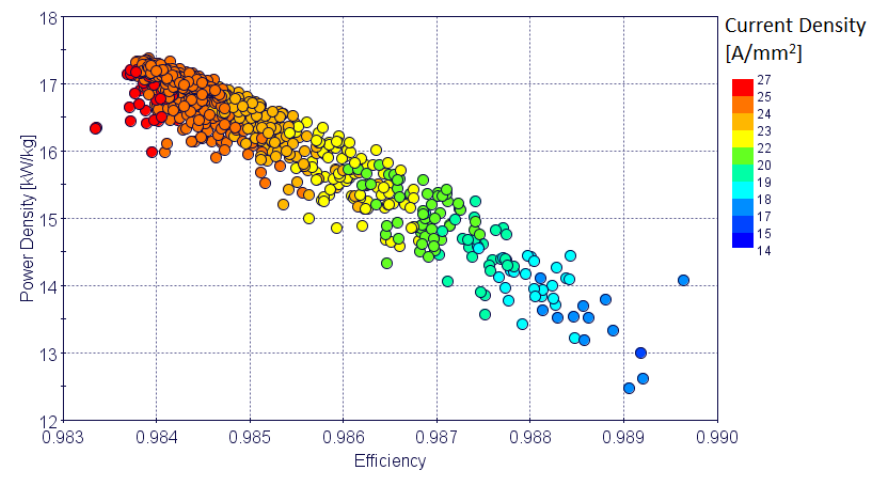

Fig. 12: The feasible designs - correlation of power density against efficiency.

The generator has a stator outer diameter of $378 \mathrm{~mm}$, a stator bore diameter of $273 \mathrm{~mm}$, while the axial length of the stator stack is $2 \times 105 \mathrm{~mm}$, as shown in Fig. 13, considering the cooling channel in the mid-axial section of the core, as shown in Fig. 3.

Table 6 - THE MAIN OUTPUT PARAMETERS OF THE FINAL DESIGN

\begin{tabular}{lc}
\hline \multicolumn{1}{c}{ Basic Output Parameters } & Value \\
\hline Phase current [RMS] & $414 \mathrm{~A}$ \\
\hline Phase Voltage [RMS] & $491 \mathrm{~V}$ \\
\hline Phase bEMF [RMS] & $404 \mathrm{~V}$ \\
\hline Power & $4 \mathrm{MW}$ \\
\hline Torque & $2548 \mathrm{Nm}$ \\
\hline Power Factor & 0.82 \\
\hline Current Density & $27.5 \mathrm{Arms} / \mathrm{mmcu}^{2}$ \\
\hline Power Density & $17.3 \mathrm{~kW} / \mathrm{kg}$ \\
\hline Iron Loss & $8.8 \mathrm{~kW}$ \\
\hline Copper Loss & $60.3 \mathrm{~kW}$ \\
\hline Total Electrical Loss & $69.1 \mathrm{~kW}$ \\
\hline Efficiency & 0.983 \\
\hline Iron Mass & $56.4 \mathrm{~kg}$ \\
\hline Magnet Mass & $34.7 \mathrm{~kg}$ \\
\hline Copper Mass & $21.8 \mathrm{~kg}$ \\
\hline Active Mass & $113 \mathrm{~kg}$ \\
\hline Passive Mass & $119 \mathrm{~kg}$ \\
\hline Total Mass & $232 \mathrm{~kg}$ \\
\hline \hline
\end{tabular}

From Fig. 13 it can be noted that the PM array has a flat bottom for mechanical and practical manufacturing purposes. The flat bottom simplifies the assembly procedure since three magnet segments can be stacked and glued to the rotor core together as a single pack. It should be mentioned that the PMs are axially segmented in $2 \mathrm{~mm}$ sections in order to prevent additional eddy current losses in the magnets. The PM design has been validated against demagnetization against both currents and high temperature effects. The insulation system comprises Nomex material that is used as phase-to-ground liner and Kapton tape wrapped around the Litz wire bundles as shown in Fig. 13. The gap in the middle of the slot provides a path for the coolant flow. 


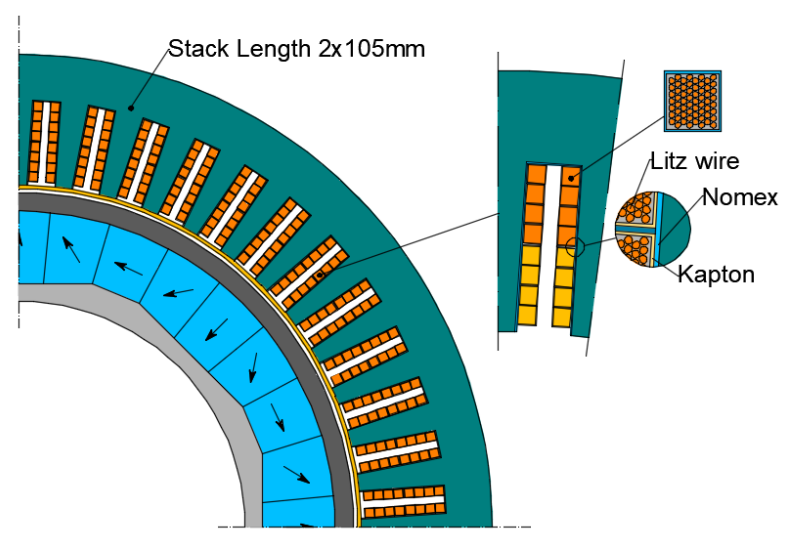

Fig. 13: Schematic of the final machine design.

\section{EXPERIMENTAL VALIDATION}

It should be noted that the stator core of the first prototype presented in this work is made from $\mathrm{SiFe}$ electrical steel grade M235-35A. This is to avoid the unpredictable challenges and risks related to the manufacturing and assembly procedures and minimise the risk of damaging an expensive $\mathrm{CoFe}$ core material. All the experiments described hereafter were performed with a SiFe stator core in the machine. The assembly of the second prototype with the CoFe stator core is in progress and it will be tested in the near future.

Fig. 14 shows the manufactured 4MW generator, assembled in-house. The total mass of the designed generator, including passive components, is $249 \mathrm{~kg}$ which is close to the modelled value of $232 \mathrm{~kg}$. The active mass of the prototype is $117 \mathrm{~kg}$, approximately $47 \%$ of the total mass, while the passive mass is $132 \mathrm{~kg}$ or about $53 \%$ of the total mass.

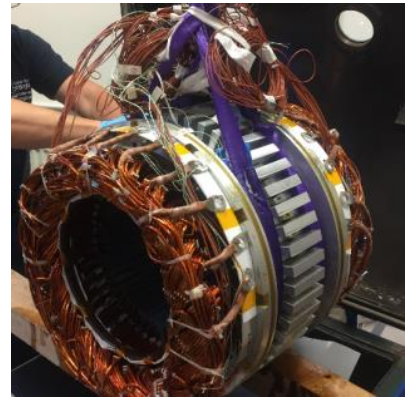

a)

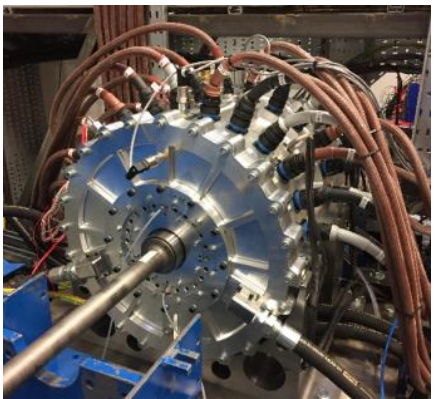

b)
Fig. 14: Stator assembly (a) and the developed generator on a test rig (b).

A series of experiments were performed to validate the machine characteristics. The experimental test rig includes the dynamometer drive with a nominal power of $860 \mathrm{~kW}$, the modular $4 \mathrm{MW}$ multiphase-multilevel converter, a $256 \mathrm{~kW}$ bidirectional DC power supply and the cooling system. Fig. 15 highlights the constituent components of the overall generation system.

The first test was the no-load bEMF measurements. The machine was coupled with the induction motor and spun up to $3000 \mathrm{rpm}$ while the bEMF waveforms of 4 different lines were recorded. The measured bEMF is in a good agreement with the simulation. The measured and simulated line-to-line bEMF harmonic spectrum at $2000 \mathrm{rpm}$ is shown in Fig. 16. The acquired bEMF waveform is sinusoidal without significant contribution of high order harmonics Fig. 17. The total harmonic distortion (THD) is $1.88 \%$.

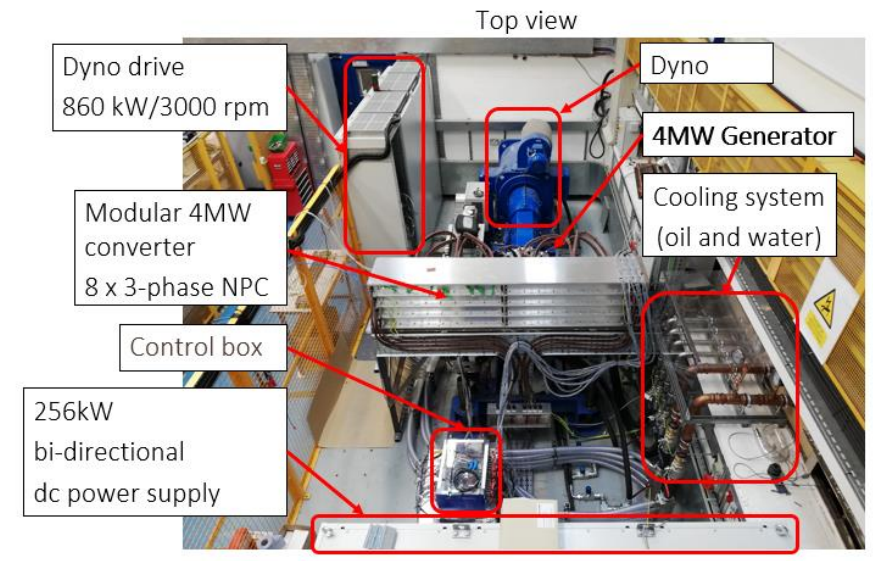

Fig. 15: High power area test facility: $860 \mathrm{~kW}$ dynamometer and test rig layout.

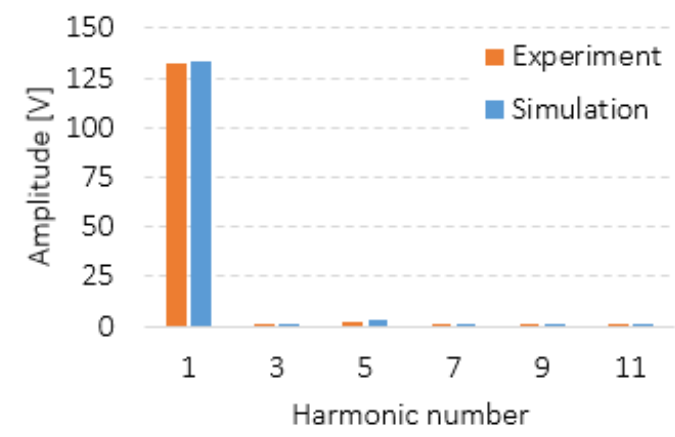

Fig.16: Line-to-line bEMF harmonic spectrum at $2000 \mathrm{rpm}$.

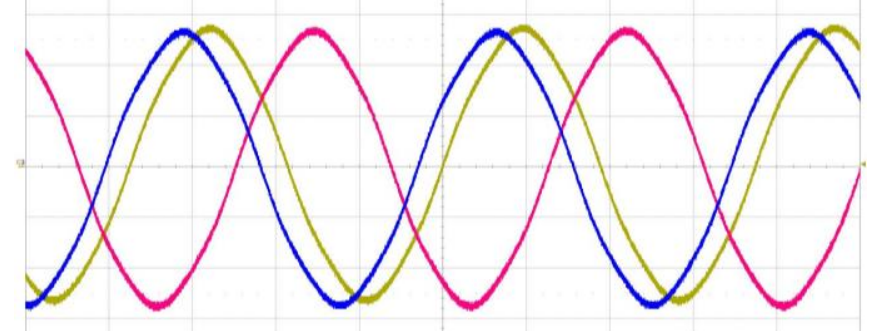

Fig.17: Measured line-to line bEMF waveforms at 2000rpm (Ch1 - yellow $\mathrm{bEMF}_{\mathrm{AB}}$-echo, $\mathrm{Ch} 2$ - red - bEMF $\mathrm{BC}_{\mathrm{BC}}$-echo, Ch3 - blue - bEMF $\mathrm{AB}_{\mathrm{AB}}$-bravo); $\mathrm{x}$ and y axes are time $[\mathrm{ms}](50 \mathrm{~ms} / \mathrm{div})$ and voltage $[\mathrm{V}](50 \mathrm{~V} / \mathrm{div})$, respectively.

The torque characteristic was measured at a constant speed of $500 \mathrm{rpm}$, with the power supply input DC voltage of $800 \mathrm{~V}$, as shown in Fig. 18. The Iq current was gradually increased from 100 A to $600 \mathrm{~A}$ for all $8 \times 3$-phases while the dynamometer speed was kept constant via a speed control loop. The nonlinear behaviour of the torque curve, due to the stator core saturation effect, can be observed at higher current. The measured torque deviation from the simulation result at the maximum load was $5.3 \%$. 


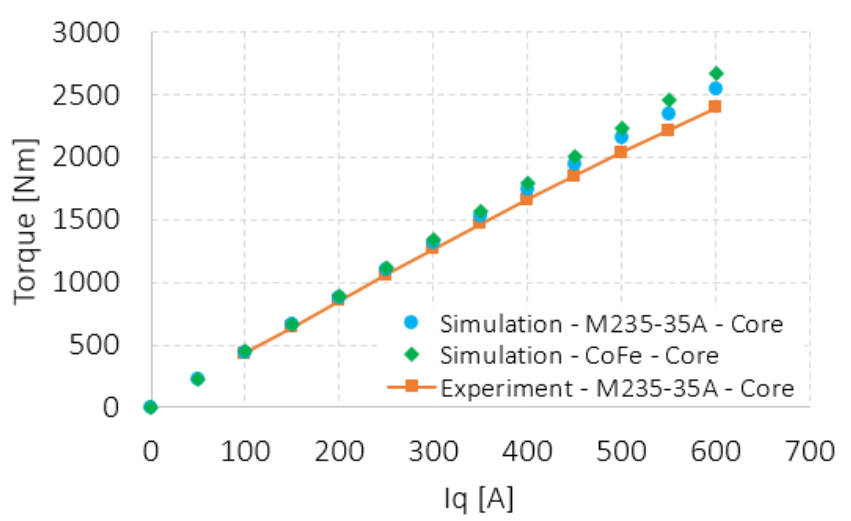

Fig.18: Torque-current characteristic at 500rpm, $800 \mathrm{Vdc}$.

The acquired current waveforms related to the motoring mode with the load torque of $2400 \mathrm{Nm}$ are presented in Fig. 19.

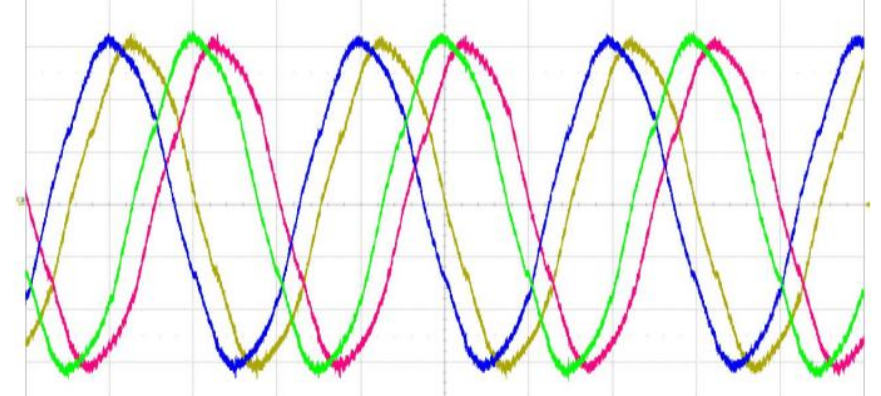

Fig.19: The acquired phase current waveforms at the motoring mode (Iq $=$ $600 \mathrm{Apk}, 500 \mathrm{rpm}, 2400 \mathrm{Nm}, 800 \mathrm{Vdc}$ ); Ch1 yellow: echo-npc2-phB, Ch2 red: echo-npc2-phC, Ch3 blue:bravo-npc2-phB, Ch4 green: bravo-npc2-phC; ); $\mathrm{x}$ and y axes are time $[\mathrm{ms}]-10 \mathrm{~ms} / \mathrm{div}$ and current $[\mathrm{A}]-200 \mathrm{~A} / \mathrm{div}$, respectively.

A recirculating power test was performed as described in detail in [21]. For the recirculating power of $350 \mathrm{~kW}$ the efficiency of the overall system, machine plus converter, reached the maximum $92.5 \%$ Fig. 20 . The test was carried out at $7500 \mathrm{rpm}$, with a DC link voltage of $1.5 \mathrm{kV}$ and a reference torque varying from $100 \mathrm{Apk}$ to $500 \mathrm{Apk}$. For the highest power test, the total losses of the series drive system are about $85 \mathrm{~kW}$. The split of the losses, according to the simulation results are $53.9 \mathrm{~kW}$ ( $64.7 \%$ of the total) in the machine. A series of thermal tests will be carried out in the near future to segregate the machine and converter losses by using a colorimetric method and asses the efficiency of machine and converter separately.

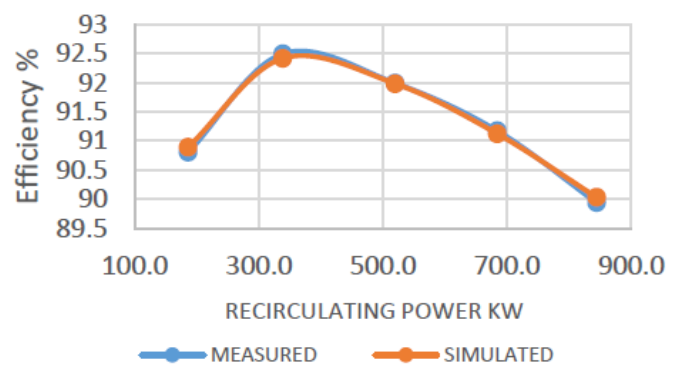

Fig.20: The acquired phase current waveforms at the motoring mode ( $\mathrm{Iq}=$ $600 \mathrm{Apk}, 500 \mathrm{rpm}, 2400 \mathrm{Nm}, 800 \mathrm{Vdc}$ ); Ch1 yellow: echo-npc2-phB, Ch2 red: echo-npc2

\section{CONCLUSIONS}

The presented work contains the description of the optimisation procedure and key steps in the development of a $4 \mathrm{MW}$ class high power density generator. The optimisation procedure comprises three stages: (1) simple and fast analytical calculator, (2) subdomain analytical modelling and (3) FEA. At the first stage, a broad range of possible numbers of pole pairs (from 2 to 6) and slots (1 and 2 slots per pole per phase) were considered; seeking the configuration with the highest power density whilst meeting the converter requirements together with the efficiency, mechanical and thermal constraints. As the result of the first stage of optimisation, the configuration with 4 pole pairs and 2 SPP that predicted a power density of 15 $\mathrm{kW} / \mathrm{kg}$ and the efficiency of $98.4 \%$ was selected and taken to the next stage of optimisation. The output of the second stage was the improved machine design with 4 PM segments per pole pitch and with the corresponding power density of $16.1 \mathrm{~kW} / \mathrm{kg}$ and $98.5 \%$ efficiency. At the third and final stage of optimisation, the slot dimensions together with the stator outer diameter and the active length were refined by an FEA optimisation considering the stator core saturation effect. As a result, the final machine has a predicted power density of 17.3 $\mathrm{kW} / \mathrm{kg}$ that corresponds to $232 \mathrm{~kg}$ of total mass and an efficiency of $98.3 \%$.

The experimental campaign confirms the key machine characteristics. The measured line-to-line bEMF has a deviation within $1.2 \%$ compared to the simulation at the tested speed range from $1000 \mathrm{rpm}$ to $3000 \mathrm{rpm}$. The load test was performed at low speed (500 rpm) and shows a 5.3\% difference when compared to the simulation at the maximum load.

It should be mentioned that the test results presented in this work were done for the first prototype with the SiFe stator core. The second prototype with $\mathrm{CoFe}$ stator core material is under development and improvements of the output characteristics of the generator compared to the first version are expected, which will be reported in subsequent publications.

\section{ACKNOWLEDGMENTS}

The authors would like to thank Mykhaylo Filipenko and Rolls-Royce Electric team for the great research collaboration. The authors would also like to thank John Hinchliffe (Senior technical manager), Kevin Last, Matthew Cooper and all the electrical and mechanical technical teams from the Power Electronics Machines and Control (PEMC) research group, Faculty of Engineering, The University of Nottingham. Their continued support with the planning, manufacturing, assembly of the prototypes and test rigs has been fundamental. The authors would like to thank Andrew Plummer and the mechanical team at Central Engineering Workshop (L2), Faculty of Engineering, The University of Nottingham, for their great technical support. 


\section{REFERENCES}

[1] “www.iata.org," IATA. Technology Roadmap, 2018., 2018. [Online].

Available:

https://www.iata.org/en/programs/environment/technologyroadmap/.

[2] "European Commission, Flightpath 2050 Europe's Vision for Aviation Report of the High Level Group on Aviation Research," Directorate-General for Mobility and Transport, 2011. [Online].

Available:

https://ec.europa.eu/transport/sites/transport/files/modes/air/doc/fligh tpath2050.pdf.

[3] K. L. Suder, "Overview of the NASA Environmentally Responsible Aviation Project's Propulsion Technology Portfolio," in 48th AIAA/ASME/SAE/ASEE, 2012.

[4] R. D. Rosario, "A future with hybrid electric propulsion systems: A NASA perspective," in Proceedings of Turbine Engine Technology Symposium (TETS), 2014.

[5] "Airbus, Rolls-Royce, and Siemens team up for electric future Partnership launches E-Fan X hybrid-electric flight demonstrator, 2017," Airbus, [Online]. Available: https://www.airbus.com/newsroom/press-releases/en/2017/11/airbus-rolls-royce--and-siemens-team-up-for-electric-future-par.html.

[6] "Clean Energy Wire. Emission-free aviation is technically feasible - DLR Researcher, 2018.," [Online]. Available: https://www.cleanenergywire.org/news/emission-free-aviationtechnically-feasible-dlr-researcher.

[7] "Zunum Aero. 2018.," [Online]. Available: https://www.aerospace-technology.com/projects/zunum-aero-hybridelectric-aircraft/.

[8] W. Cao et al, "Overview of Electric Motor Technologies Used for More Electric Aircraft (MEA)," IEEE Transactions on Industrial Electronics, vol. 59, no. 9, pp. 3523-3531, 2012.

[9] F. Finger et al, "Case Studies in Initial Sizing for Hybrid-Electric General Aviation Aircraft," in AIAA/IEEE Electric Aircraft Technologies Symposium (EATS), Cincinnati, 2018.

[10] C. L. Bowman et al, "Turbo- and Hybrid-Electrified Aircraft Propulsion Concepts for Commercial Transport," in AIAA/IEEE Electric Aircraft Technologies Symposium (EATS), Cincinnati USA, 2018.

[11] S. Øvrebø et al, Test and validation of the mark 1 (2.5 MW) Efan X generator, NATO AVT-RSY-323 Res. Symp. Hybrid/Electr. Aero-Propuls. Syst. Mil. Appl. (Session: Integr. PowerTrain 2), 2019. [12] E. Ganev, "Selecting the Best Electric Machines for Electrical Power-Generation Systems," IEEE Electrification Magazine, vol. 2, no. 4, pp. 13-22, 2014.

[13] X. Zhang, C. L. Bowman, T. C. O' Connell and K. S. Haran, "Large electric machines for aircraft electric propulsion," IET Electric Power Applications, vol. 12, no. 6, pp. 767 - 779, 2018.

[14] M. Filipenko et al, "Concept design of a high power superconducting generator for future hybrid-electric aircraft," Superconductor Science and Technology, vol. 33, no. 5, 2020.

[15] A. Perez et al, "Rotor Cooling Concept for the ASuMED Superconductive Motor," IOP Conference Series: Materials Science and Engineering, no. 502, p. 012139, 2018.

[16] A. El-Refaie and M. Osama, "High specific power electrical machines: A system perspective," CES Transactions on Electrical Machines and Systems, vol. 3, no. 1, pp. 88 - 93, 2019.

[17] M. van der Geest et al, "Power Density Limits and Design Trends of High-Speed Permanent Magnet Synchronous Machines," IEEE Transactions on Transportation Electrification, vol. 1, no. 3, pp. 266 - 276, 2015.
[18] D. Golovanov, L. Papini, D. Gerada, Z. Xu and C. Gerada, "Multidomain Optimization of High-Power-Density PM Electrical Machines for System Architecture Selection," in IEEE Transactions on Industrial Electronics, vol. 65, no. 7, pp. 5302 - 5312, 2018.

[19] D. Golovanov, Z. Xu, D. Gerada, M. Degano, G. Vakil and C. Gerada, "The Influence of Stator Material on the Power Density and Iron Loss of a High-Performace Starter-Generator for More Electric Aircraft," in 21st International Conference on Electrical Machines and Systems (ICEMS), Jeju, South Korea, 2018.

[20] S. Bozhko et al., "Development of Aircraft Electric StarterGenerator System Based on Active Rectification Technology," in IEEE Transactions on Transportation Electrification, vol. 4, no. 4, pp. 985-996, Dec. 2018, doi: 10.1109/TTE.2018.2863031.

[21] A. Trentin et al, "Research and Realisation of High-Power Medium Voltage Active Rectifier Concepts for Future HybridElectric Aircraft Generation," in IEEE Transactions on Industrial Electronics, vol. 10.1109/TIE.2020.3040692, no. Early Access, 2020.

[22] L. J. Wu et al, "Analytical model for predicting magnet loss of surface-mounted permanent magnet machines accounting for slotting effect and load," IEEE Trans. Magn., vol. 48, no. 1, p. 107-117, 2012. [23] C. Poloni et al, "GA coupled with computationally expensive simulations: tools to improve efficiency.," in Genetic algorithms and evolution strategy in engineering and computer science: recent advances and industrial applications, Chichester, UK, John Wiley \& Sons, 1996, p. 267-288.

[24] Z. Xia et al, "Analytical Magnetic Field Analysis of Halbach Magnetized Permanent-Magnet Machines," IEEE Trans. Magnetics, vol. 40, no. 4, pp. 1864-1872, 2004.

[25] W. Tong, Mechanical Design of Electric Motors, Miami: CRC Press Taylor \& Francis Group, 2014.

[26] T. Lubin and S. Mezani, "2-D Exact Analytical Model for Surface-Mounted Permanent-Magnet Motors With Semi-Closed Slots," IEEE Transactions on Magnetics, vol. 47, no. 2, pp. 479 - 492, 2011.

[27] L. J. Wu et al, "Subdomain Model for Predicting Armature Reaction Field of Surface-Mounted Permanent-Magnet Machines Accounting for Tooth-Tips," IEEE Transactions on Magnetics, vol. 47, no. 4, pp. 812 - 822, 2011.

[28] D. Golovanov and C. Gerada, "An Analytical Subdomain Model for Dual-Rotor Permanent Magnet Motor With Halbach Array," in IEEE Transactions on Magnetics, vol. 55, no. 12, 2019.

[29] A. Bardalai, D. Gerada, D. Golovanov, Z. Xu, X. Zhang, J. Li, H. Zhang and C. Gerada, "Reduction of Winding AC Losses by Accurate Conductor Placement in High Frequency Electrical Machines," in IEEE Transactions on Industry Applications, vol. 56, no. 1, pp. 183 - 193, 2020.

[30] M. Dorrell et al, "Proximity losses in the windings of high speed brushless permanent magnet AC motors with single tooth windings and parallel paths," IEEE Trans. Magn, vol. 49, no. 7, p. 3913-3916, 2013.

[31] S. Iwasaki et al, "Influence of PWM on the proximity loss in permanent-magnet brushless AC machines," in IEEE Trans. Ind. Appl, vol. 45, no. 4, p. 1359-1367, 2009.

[32] A. Bardalai, Z. Xu, J. Li, D. Gerada, C. Gerada, D. Golovanov and H. Zhang, "The Influence of Strands and Bundle-Level Arrangements of Magnet Wires on AC Losses in the Winding of High - Speed Traction Machine," in 2018 21st International Conference on Electrical Machines and Systems (ICEMS), Jeju, South Korea, 2018.

[33] A. Bardalai, X. Zhang, T. Zou, D. Gerada, J. Li and C. Gerada, "Comparative Analysis of AC losses with round magnet wire and Litz wire winding of a High - Speed PM Machine," in 22nd International 
Conference on Electrical Machines and Systems (ICEMS), Harbin, China, China, 2019.

[34] D. Gerada, A. Mebarki, N. L. Brown, C. Gerada, A. Cavagnino and A. Boglietti, "High-Speed Electrical Machines: Technologies, Trends, and Developments," in IEEE Transactions on Industrial Electronics, vol. 61, no. 6, pp. 2946-2959, June 2014.

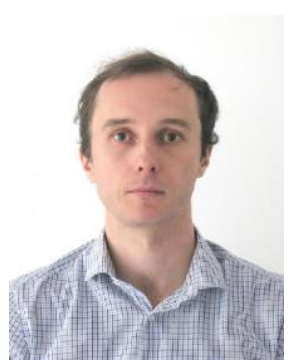

Dmitry Golovanov received the Ph.D. degree in superconducting electrical machines from Moscow Aviation Institute, Moscow, Russia, in 2011.,He has an experience of working in industry as a Researcher in VNIIEM Corporation JSC, Russia, in the field of design of electrical machines and in Samsung SDI, South Korea, in the field of Li-ion batteries. He is currently a Research Fellow in the University of Nottingham, Nottingham, UK. His main research interests include high power density electric machines for aerospace and automotive industry application, and superconducting electrical machines.

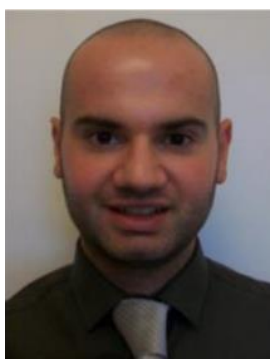

David Gerada received the Ph.D. degree in highspeed electrical machines from University of Nottingham, Nottingham, U.K., in 2012. From 2007 to 2016, he was with the R\&D Department at Cummins, Stamford, U.K., first as an Electromagnetic Design Engineer (2007- 2012), and then as a Senior Electromagnetic Design Engineer and Innovation Leader (2012- 2016). At Cummins, he pioneered the design and development of high-speed electrical machines, transforming a challenging technology into a reliable one suitable for the transportation market, while establishing industrywide-used metrics for such machinery. In 2016, he joined the University of Nottingham where he is currently a Principal Research Fellow, responsible for developing state-of-the-art electrical machines for future transportation which push existing technology boundaries, while propelling the new technologies to higher technology readiness levels. Dr. Gerada is a Chartered Engineer in the U.K. and a member of the Institution of Engineering and Technology.

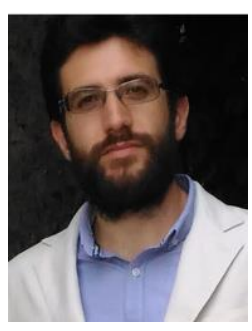

Giacomo Sala received the B. Sc. in Power Engineering in 2012 from the University of Bologna, Italy, the M. Sc. degree with honors in Electrical Engineering in 2014 and the Ph.D. in Electrical Machines and Drives in 2018, from the same university. He has been a research associate/fellow until 2019 in the Power Electronics, Machines and Control Group, Dept. of Electrical and Electronic Engineering, The University of Nottingham, UK. In 2019 he joined the Dept. of Electrical, Electronic, and Information Engineering "G. Marconi" of the University of Bologna, where he is currently an assistant professor. His research interests include design, modelling and control of multiphase electrical machines, fault tolerant controls and fault diagnosis of electric drives.

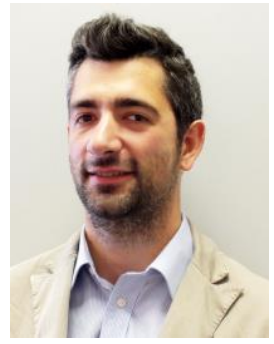

Michele Degano (M'15) received his Master's degree in Electrical Engineering from the University of Trieste, Italy, in 2011, and his Ph.D. degree in Industrial Engineering from the University of Padova, Italy, in 2015. Between 2014 and 2016, he was a post-doctoral researcher at The University of Nottingham, UK, where he joined the Power Electronics, Machines and Control (PEMC) Research Group. In 2016 he was appointed Assistant Professor in Advanced Electrical Machines, at The University of Nottingham, UK. He was promoted Associate Professor in 2020. His main research focuses on electrical machines and drives for industrial, automotive, railway and aerospace applications, ranging from small to large power. He is currently the PEMC Director of Industrial Liaison leading research projects for the development of hybrid electric aerospace platforms and electric transports.

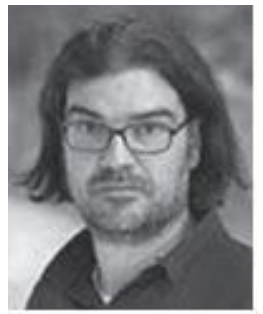

Andrew Trentin received the "Laurea" Master's degree and $\mathrm{Ph} . \mathrm{D}$. degree in electrical engineering from the University of Bologna, Bologna, Italy, in 2001 and 2005, respectively.

[1] Since 2005, he has been a Research Fellow in the Power Electronics, Machines and Control Research Group, at The University of Nottingham, UK, and promoted to Senior Research Fellow in 2012. His research interests are power electronics and electrical drives for different applications and in direct ac/ac

matrix converters.

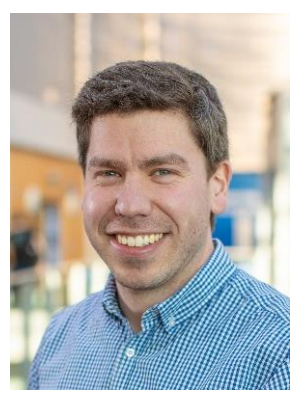

Peter H. Connor received an M.Eng. and Ph.D. from the Department of Mechanical, Materials and Manufacturing Engineering Department, University of Nottingham, UK, in 2009 and 2014, respectively. He is a Senior Research Fellow in the Power Electronics, Machines and Control Research Group in the Faculty of Engineering at the University of Nottingham. His research interests are mechanical design and thermal management of electrical machines for industrial power generation and high-speed, high powerdensity traction and aerospace applications.

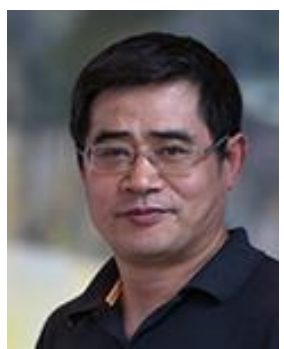

Zeyuan Xu, IEEE member, received his $\mathrm{PhD}$. degree in mechanical engineering from the University of Manchester, Manchester, U.K. in 2002. He subsequently worked as a Research Fellow at UMIST, Brunel University, and the University of Nottingham. He is currently a Senior Research Fellow in thermo-mechanical design of high speed electrical machines within the PEMC group at the University of Nottingham, Nottingham, U.K.

His main research interests include turbulent thermo-fluid flow, heat transfer enhancement, thermal management of advanced electrical machines and power electronics, electrical machine structure analysis, rotor dynamics analysis and mechanical design.

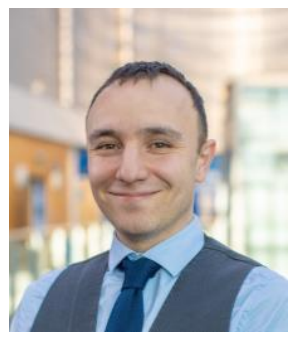

Antonino La Rocca received his Ph.D. from the Department of Mechanical, Materials and Manufacturing Engineering Department, University of Nottingham, UK, in 2016. He is a Research Fellow in the Fluids and Thermal Engineering Research Group and the Power Electronics, Machines and Control Research Group in the Faculty of Engineering at the University of Nottingham. His research field is the thermo-mechanical modelling and design of high speed and high power dense electrical machines and power electronics designs for advanced generation and propulsion systems by the use of Lumped Parameters Thermal networks (LPTN) and Computational Fluid Dynamics (CFD) and FEA.

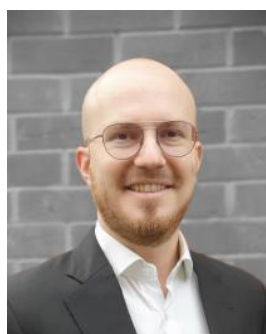

Alessandro Galassini (S'13-M'20) received the master's degree in mechatronic engineering from the University of Modena and Reggio Emilia, Reggio Emilia, Italy, in 2012, and the Ph.D. degree in power sharing for multi-three-phase electrical machines from the University of Nottingham, Nottingham, UK, in 2017. He is currently a Research Fellow with the Power Electronics, Machines and Control Group, The University of Nottingham. His research interests include control of electrical drives for future transportation systems. 


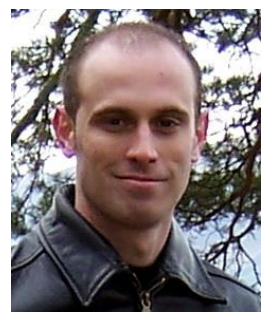

Luca Tarisciotti (S'12-M'15) received the Master's degree in Electronic Engineering from The University of Rome "Tor Vergata" in 2009 and his $\mathrm{Ph} . \mathrm{D}$. degree in Electrical and Electronic Engineering from the PEMC group, University of Nottingham in 2015. In the same year he became Research Fellow at the University of Nottingham, UK, until 2018. He is currently working as Assistant Professor at the University Andres Bello, Santiago, Chile. His research interests include Matrix converters, DC/DC converters, Multilevel converters, Advanced modulation schemes, and Advanced power electronics converter control.

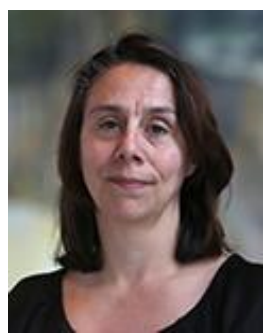

Carol N. Eastwick received his Master's degree in Electrical Carol N. Eastwick received her BEng and $\mathrm{PhD}$ in Mechanical Engineering in 1990 (Imperial College) and 1995 (University of Nottingham). She is a Professor at the University of Nottingham and Head of the Gas Turbine Transmissions Research Centre. Her research interests include two phase fluid flows associated with solid combustion and cooling/thermal management and she has worked on modelling and experimental investigations of thermofluids associated with rotating machinery for over twenty years.

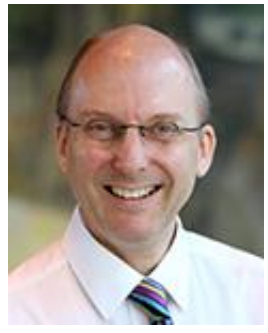

Stephen J. Pickering obtained a BSc in Mechanical Engineering in 1979 and a $\mathrm{PhD}$ in Mechanical Engineering in 1984 both from the University of Nottingham. Following several years in industry he was appointed as a lecturer at the University of Nottingham in 1988 where he currently holds the Hives Chair in Mechanical Engineering. He has extensive research interests in the area of thermofluids and has undertaken research into thermal management of electric machines and power electronics systems for over 25 years.

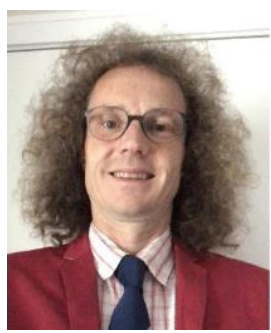

Prof Pat Wheeler received his BEng [Hons] degree in 1990 from the University of Bristol, UK. $\mathrm{He}$ received his $\mathrm{PhD}$ degree in Electrical Engineering for his work on Matrix Converters from the University of Bristol, UK in 1994. In 1993 he moved to the University of Nottingham and worked as a research assistant in the Department of Electrical and Electronic Engineering. In 1996 he became a Lecturer in the Power Electronics, Machines and Control Group at the University of Nottingham, UK. Since January 2008 he has been a Full Professor in the same research group.

He was Head of the Department of Electrical and Electronic Engineering at the University of Nottingham from 2015 to 2018. He is currently the Head of the Power Electronics, Machines and Control Research Group, Global Director of the University of Nottingham's Institute of Aerosapce Technology and is the Li Dak Sum Chair Professor in Electrical and Aerospace Engineering. He is a member of the IEEE PELs AdCom and was an IEEE PELs Distinguished Lecturer from 2013 to 2017. He has published 750 academic publications in leading international conferences and journals.

Prof Pat Wheeler was involved in the writing of the rules for TTXGP, the first electric superbike Grandprix, in 2009. Since then he has been involved in the regulations for electric superbike racing as well as founding the University of Nottingham's Electric Superbike team, which has finished on the podium in 3 out of the last 4 years as well as being the European Champions two years in a row. He has also been involved in Solar Cars, initially as the international observer for the inaugural Chilean Solar Challenge in 2010.

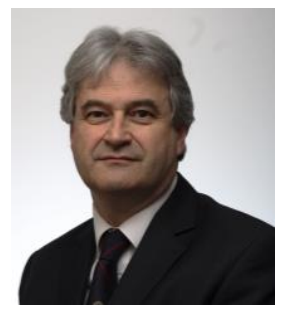

Jon Clare (M'90-SM'04) was born in Bristol, UK, in 1957. He received the $\mathrm{BSc}$ and $\mathrm{PhD}$. degrees in electrical engineering from the University of Bristol, UK, in 1979 and 1990, respectively. From 1984 to 1990 , he was a Research Assistant and Lecturer with the University of Bristol, where he was involved in teaching and research on power electronic systems. Since 1990, he has been with the Faculty of Engineering at the University of Nottingham, UK. He is currently Professor of Power Electronics and is the Head of the Electrical and Electronic Engineering Department. He is a member of the Power Electronics, Machines and Control Research Group at Nottingham. His research interests are in power-electronic converters and their applications and control. Jon Clare is a Fellow of the IET and the recipient of a Royal Society Wolfson Research Merit Award.

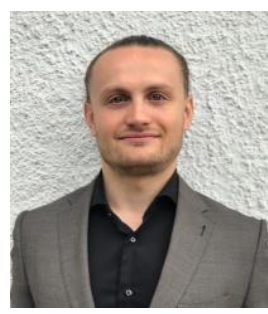

Mykhaylo Filipenko was the director for the Center of Competence Electric Machines "Higher Power" within Siemens eAircraft and later Rolls-Royce Electric. His research focus is two-fold. On the hand, it is the research and development of multi-megawatt motors and generators for future electric and hybridelectric aircraft. This includes in particular new machine topologies, high speed electric machines, superconducting electric machines, high voltage insulation technology and light-weight design. One the other hand, he drives the digitalization of the R\&D processes by establishing the digital twin for electric machines and the holistic optimization of drive-train systems by physics-based bottom-up modelling. He holds a $\mathrm{PhD}$ in experimental particle physics which he received after performing experiments in different labs such as FermiLab, CERN, NIKHEF and DESY,

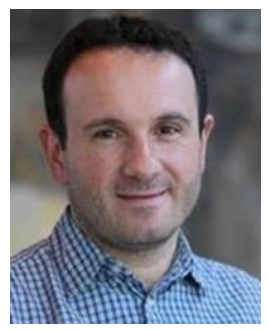

Chris Gerada (SM'12) is an Associate Pro-ViceChancellor for Industrial Strategy and Impact and Professor of Electrical Machines. His principal research interest lies in electromagnetic energy conversion in electrical machines and drives, focusing mainly on transport electrification. He has secured over $£ 20 \mathrm{M}$ of funding through major industrial, European and UK grants and authored more than 350 referred publications. He received the $\mathrm{Ph} . \mathrm{D}$. degree in numerical modelling of electrical machines from The University of Nottingham, Nottingham, U.K., in 2005. He subsequently worked as a Researcher with The University of Nottingham on high-performance electrical drives and on the design and modelling of electromagnetic actuators for aerospace applications. In 2008, he was appointed as a Lecturer in electrical machines; in 2011, as an Associate Professor; and in 2013, as a Professor at The University of Nottingham. He was awarded a Research Chair from the Royal Academy of Engineering in 2013. Prof. Gerada served as an Associate Editor for the IEEE Transactions on Industry Applications and is the past Chair of the IEEE IES Electrical Machines Committee. 